Check for updates

Cite this: Sustainable Energy Fuels, 2017, 1, 1339

Received 5th June 2017

Accepted 28th June 2017

DOI: $10.1039 / \mathrm{c} 7 \mathrm{se} 00277 \mathrm{~g}$

rsc.li/sustainable-energy

\section{Candidate photoferroic absorber materials for thin- film solar cells from naturally occurring minerals: enargite, stephanite, and bournonite $\uparrow$}

\author{
Suzanne K. Wallace, (D) ab Katrine L. Svane, ${ }^{a}$ William P. Huhn, (D) ${ }^{c}$ Tong Zhu, ${ }^{c}$ \\ David B. Mitzi, (D) ${ }^{\mathrm{cd}}$ Volker Blum (D) ${ }^{\mathrm{cd}}$ and Aron Walsh (iD *be
}

\begin{abstract}
To build on the success of other mineral systems employed in solar cells, including kesterites $\left(\mathrm{Cu}_{2} \mathrm{ZnSnS}_{4}\right)$ and herzenbergite ( $\mathrm{SnS})$, as well as mineral-inspired systems such as lead halide perovskites $\left(\mathrm{CH}_{3} \mathrm{NH}_{3} \mathrm{Pbl}_{3}\right)$, we have searched for photoactive minerals with the additional constraint that a polar crystal structure is adopted. Macroscopic electric fields provide a driving force to separate electrons and holes in semiconductor devices, while spontaneous lattice polarisation in polar semiconductors can facilitate microscopic photo-carrier separation to enhance carrier stability and lifetimes. We identify enargite $\left(\mathrm{Cu}_{3} \mathrm{AsS}_{4}\right)$, stephanite $\left(\mathrm{Ag}_{5} \mathrm{SbS}_{4}\right)$, and bournonite $\left(\mathrm{CuPbSbS}_{3}\right)$ as candidate materials and explore their chemical bonding and physical properties using a first-principles quantum mechanical approach.
\end{abstract}

\section{Introduction}

A key component of the pathway towards terawatt-scale solar power generation is the continued reduction in cost, whilst also improving the performance of solar modules. ${ }^{1}$ The search for candidate 'thin-film' photovoltaic (PV) materials that are able to absorb sunlight more strongly than silicon is an active area of research to enable the fabrication of cost-effective and highlyefficient solar cell devices. ${ }^{2}$ Common ways to screen for such materials include looking for systems with an optical band gap that is direct and well-matched to the solar spectrum ${ }^{3}$ and with an abrupt onset in the absorption spectrum. ${ }^{4}$

Interest in this field has intensified in recent years with the remarkable power conversion efficiencies (PCEs) achieved with lead halide perovskites. PCEs of around $20 \%$ (ref. 5 and 6) have been achieved over a much shorter period of development than has been needed for many other PV technologies to achieve the same level of performance. ${ }^{7}$ Lead halide perovskites currently out-perform many other materials that also meet the aforementioned screening criteria, such as $\mathrm{Cu}_{2} \mathrm{ZnSn}(\mathrm{S}, \mathrm{Se})_{4}$ (ref. 8) and SnS. ${ }^{9}$ Of this class of materials, methylammonium lead

${ }^{a}$ Department of Chemistry, Centre for Sustainable Chemical Technologies, University of Bath, Claverton Down, Bath, BA2 7AY, UK

${ }^{b}$ Department of Materials, Imperial College London, Exhibition Road, London SW7 2AZ, UK. E-mail: a.walsh@imperial.ac.uk

${ }^{c}$ Department of Mechanical Engineering and Materials Science, Duke University, Durham, North Carolina 27708, USA

${ }^{d}$ Department of Chemistry, Duke University, Durham, North Carolina 27708, USA ${ }^{e}$ Global $E^{3}$ Institute, Department of Materials Science and Engineering, Yonsei University, Seoul 03722, Korea

$\dagger$ Electronic supplementary information (ESI) available. See DOI: $10.1039 / \mathrm{c} 7 \mathrm{se} 00277 \mathrm{~g}$ iodide $\left(\mathrm{CH}_{3} \mathrm{NH}_{3} \mathrm{PbI}_{3}\right.$ or $\left.\mathrm{MAPbI}_{3}\right)$ particularly stands out for its champion device efficiencies. ${ }^{6}$

The long minority-carrier lifetimes of 280 ns (ref. 10) and diffusion lengths up to 175 microns (ref. 11) demonstrated by $\mathrm{MAPbI}_{3}$-based devices are comparable with the best singlecrystal semiconductors, ${ }^{12}$ even with low-cost solution processing fabrication methods from which one would usually expect to produce a lower-quality defective material. In contrast, other candidate thin-film PV materials such as $\mathrm{Cu}_{2} \mathrm{ZnSn}(\mathrm{S}, \mathrm{Se})_{4}$ (ref. 8) and $\mathrm{SnS}^{9}$ suffer from short minority carrier lifetimes and diffusion lengths and, ultimately, large open-circuit voltage deficits in photovoltaic devices. The difference in behaviour can be attributed to 'defect tolerance'. Either the formation of detrimental defects are avoided (e.g. due to high formation energies) or their effects are minimised (due to their shallow nature within the band gap or to effective dielectric screening). It has also been suggested that the presence of polar domains in $\mathrm{MAPbI}_{3}$ could contribute to the low recombination rate (and hence long carrier lifetimes) due to the enhanced spatial separation of carriers. ${ }^{13}$ The presence of macroscopic ferroelectricity in hybrid perovskites remains a matter of research and debate, but there is growing evidence supporting polar domains at room temperature. ${ }^{\mathbf{1 4 - 1 6}}$

In this study we consider only naturally occurring minerals, and so one could expect that the materials would not suffer from the same instability issues observed for lead halide perovskites. ${ }^{17}$ We start from a small dataset ${ }^{18}$ of $\sim 200$ known, naturally occurring minerals and aim to identify materials that possess many of the desirable properties for an efficient material for solar energy conversion, using screening criteria discussed in the next section. We then investigate the chemical and physical properties of three candidate systems using a first- 
principles quantum mechanical approach to assess if these materials are likely to be capable of producing efficient photovoltaic devices.

\section{Search for light absorbing polar minerals}

\subsection{Mineral screening criteria}

Our screening criteria is outlined in the Venn diagram shown in Fig. 1 and the rationale behind our screening procedure is outlined below. The candidate materials we identified from a dataset of 193 naturally occurring multi-component minerals ${ }^{18}$ are those that could both absorb light within the energy range that makes up the majority of the solar spectrum and possibly exhibit ferroelectricity. The combination of light absorption, semiconductivity, and ferroelectricity in a single material can give rise to novel photoferroic effects. ${ }^{19}$

The most fundamental property to consider for an efficient $\mathrm{PV}$ material is an optical band gap that is direct with a magnitude within a range that is well-matched to the solar spectrum. The optimal energy range for the optical band gap of singlejunction solar cells is approximately 1.0 to $1.7 \mathrm{eV}^{20}{ }^{20}$ The streak colour of a mineral can be indicative of visible light absorption. The streak colour is that of the crushed powder, usually identified by producing a streak across a porcelain tile. While the observed colour of a mineral in massive form can vary considerably between different samples, the colour of the streak remains consistent. A mineral with a dark streak colour implies, but does not guarantee, that it will possess a band gap within the optimal range for the absorption of sunlight. We obtained information on the streak colour of the minerals from ref. 18 and this formed our first screening criterion, reducing the dataset from 193 to 36 minerals.

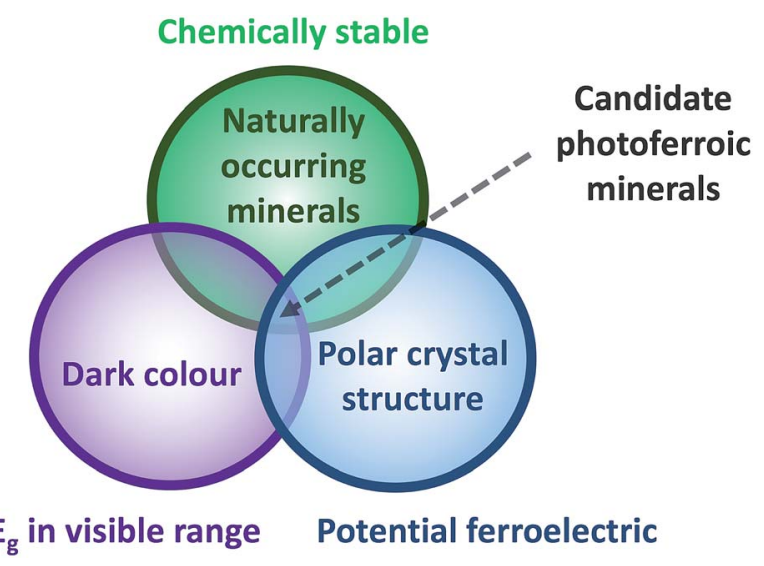

Fig. 1 Venn diagram outlining our screening criteria used to extract candidate photoferroic materials from a sample of 193 naturally occurring minerals, which we could expect to be thermodynamically stable compounds. A mineral with a dark streak colour suggests that it will possess a band gap within the energy range of visible light. Similarly, a polar crystal structure is a necessary, but not sufficient, condition for a material to exhibit ferroelectricity.
Our second screening criterion is the potential to exhibit ferroelectricity. A ferroelectric material is one that exhibits a spontaneous electric dipole moment within the unit cell, and so this is present even without the application of an electric field, but the direction of polarisation can be changed when an external electric field is applied. To identify candidate ferroelectric materials, we screen the space groups of materials to search for those that adopt crystal structures with a polar point group. This screening criterion then limited our dataset from 36 to 4 . However, we discounted $\mathrm{ZnS}$ from our study because it is known to be a wide band gap semiconductor when prepared in pure form.

A polar point group is a necessary but not sufficient property for a material to exhibit ferroelectricity and so acts as a good starting point for further study of the materials. Desirable effects could be obtained with local polarisation alone, once the correlation length of spontaneous polarisation is sufficient to interact with electron and hole carriers (typically tens of $\mathrm{nm}$ ). Furthermore, polar structures lack a centre of inversion symmetry and so they are not bound by the same optical selection rules, which could reduce the likelihood of dipole-disallowed transitions ${ }^{21}$ and the associated reduction in the strength of the onset of absorption for direct gap materials as outlined by $\mathrm{Yu}$ and Zunger in their spectroscopically limited maximum efficiency (SLME) metric. ${ }^{4}$

\subsection{Photoferroics for PV devices}

Ferroelectric materials typically display large dielectric constants due to low-energy polarisation mechanisms. ${ }^{22}$ This can have a number of implications for carrier transport and lifetimes in PV materials, such as a reduction in the electrostatic force between an electron-hole pair (low exciton binding energies), potentially leading to a reduced rate of electron-hole recombination in the material, ${ }^{23}$ provided the nuclear subsystem is able to respond on a fast enough time scale. Also, the capture cross-section for charge carriers by a charged defect can be reduced by the charge screening in a dielectric material, possibly allowing for more defect-tolerant carrier transport. ${ }^{12}$

In addition to the desirable properties that could be expected for ferroelectric materials, there are a number of novel phenomena that have been observed in photoactive polar semiconductors that are outlined in ref. 24 , which could open up new pathways to highly efficient PV devices. The potential of utilising ferroelectric crystals for solar cells was first highlighted in the work of V. M. Fridkin, ${ }^{25,26}$ but the observation of novel photovoltaic phenomena in polar crystals dates back even earlier. The bulk photovoltaic effect (BPE) was first recorded in 1956 in $\mathrm{BaTiO}_{3},{ }^{27}$ where photovoltages were measured in un-doped single crystals. ${ }^{24}$ The BPE effect is distinct from the typical PV effect in a solar cell where the electric fields that drive photo-carrier separation are typically associated with a 'p-n' or 'p-i-n' junction. In the BPE it is the internal electric fields arising from spontaneous polarisation of the lattice that drive the photocurrent. It is therefore possible for charge-carrier generation and separation to occur simultaneously in the bulk material. It has recently been demonstrated experimentally in ferroelectric single crystals of $\mathrm{BaTiO}_{3}$ that electronhole recombination is inhibited by the presence of the internal 
fields, with recombination being rapidly accelerated after the ferroelectric dipole was switched off. ${ }^{28}$

The anomalous photovoltaic effect (APE) was first observed in PbS films in 1946 (ref. 29) and has since been reported in polycrystalline CdTe, ZnTe and InP, ${ }^{30-32}$ where photovoltages output along the polarisation direction can be significantly larger than the band gap of the material, ${ }^{33}$ which is usually the upper limit for a semiconductor PV material. ${ }^{24}$ The Shockley-Queisser limit, ${ }^{3}$ which prevents any single $\mathrm{p}-\mathrm{n}$ junction solar cell from converting more than one third of the incident light into electricity, can in principle be surpassed by exploiting such phenomena. ${ }^{34}$

Most of the commonly studied ferroelectric materials such as $\mathrm{LiNbO}_{3}$ and $\mathrm{BaTiO}_{3}$ have band gaps larger than $3 \mathrm{eV}$ and can therefore only absorb sunlight in the UV range, which accounts for only around $3.5 \%$ of the solar spectrum..$^{33}$ The efficiency of PV devices made from these materials is therefore severely limited by the large band gaps. Research efforts have gone into adjusting the optical absorption of ferroelectric materials without influencing the ferroelectric properties of the material through chemical doping or alloying. ${ }^{33}$ In $\mathrm{Bi}_{3} \mathrm{Ti}_{3} \mathrm{O}_{12}$ the optical band gap has been tuned in such a way, resulting in a decrease from $3.6 \mathrm{eV}$ to $2.7 \mathrm{eV},{ }^{35}$ although this is still considerably larger than the optimal range for a PV absorber material. There are some known ferroelectric materials with band gaps closer to the optimal range. Ferroelectricity in SbSI was studied extensively in the 1960's and has a value of approximately $2 \mathrm{eV}$ for the band gap, which can be tuned by varying the chalcogen and halide. ${ }^{36}$ The Curie temperature for the phase transition from a polar to paraelectric phase for this material has been measured to be around room temperature. ${ }^{37}$ With typical operating temperatures of solar cell devices approaching $50{ }^{\circ} \mathrm{C},{ }^{38}$ it could prove difficult to exploit the ferroelectricity of this material in a working device. As the set of materials we screened are all naturally-occurring minerals with polar structures, they may retain their polar crystal structure under typical operating conditions of a solar cell.

\subsection{Candidate minerals}

From our screening process, we identified three sulfosalt minerals: enargite $\left(\mathrm{Cu}_{3} \mathrm{AsS}_{4}\right)$, stephanite $\left(\mathrm{Ag}_{5} \mathrm{SbS}_{4}\right)$, and bournonite $\left(\mathrm{CuPbSbS}_{3}\right)$, which are shown in Fig. 2. A basic sulfosalt mineral can be defined as a ternary compound $\mathrm{A}_{x} \mathrm{~B}_{y} \mathrm{C}_{z}$, which is the case for enargite $\left(\mathrm{Cu}_{3} \mathrm{AsS}_{4}\right)$ and stephanite $\left(\mathrm{Ag}_{5} \mathrm{SbS}_{4}\right)$. Options for species A include: $\mathrm{Cu}, \mathrm{Ag}, \mathrm{Pb}, \mathrm{Sn}, \mathrm{Mn}$, amongst others. Species B can be either: As, $\mathrm{Sb}$ or Bi. Options for species $\mathrm{C}$ includes: $\mathrm{S}$, Se and Te. It is also possible to form quaternary sulfosalt compounds from isoelectronic substitution of additional transition metals, as in the case of bournonite $\left(\mathrm{CuPbSbS}_{3}\right)$. The occurrence of these materials in nature under ambient conditions indicates thermodynamic stability. ${ }^{39}$ Although these materials are naturally occurring minerals, knowledge of their optoelectronic properties is scarce.

A very recent experimental study assessed the band gaps and photovoltaic response of six sulfide minerals, which included the three sulfosalt minerals we investigate in this study. ${ }^{40}$ However, the potential of sulfosalt minerals for PV applications was first highlighted by Dittrich et al. in 2007. ${ }^{39}$ This work and ref. 41 provide overviews of crystal growth and thin-film deposition methods that have been developed for synthesising sulfosalt layers. There are works in the literature referring to synthetic samples of enargite ${ }^{42}$ and stephanite. ${ }^{43}$ A recent study on bournonite ${ }^{44}$ also details a procedure for synthesising this material.

The possibility of using low temperature thin-film deposition conditions for sulfosalt solar cells has been highlighted. ${ }^{39}$ Such an approach could enable the use of a wide variety of substrates or to reduce the interaction with the back contact during deposition, which is believed to be detrimental in $\mathrm{Cu}_{2}$ $\mathrm{ZnSnS}_{4}$ devices with the Mo back contact reacting with the absorber layer to form $\operatorname{MoS}_{2} \cdot{ }^{45}$ However, it is worth noting that the mineral class of 'sulfosalts' contains materials with a diverse range of crystal structures; therefore the extent of the similarity of physical properties of different sulfosalt materials is not clear.

\section{Computational details}

\subsection{Density functional theory}

The electronic structure of the three candidate photoferroic materials was calculated using the FHI-aims ${ }^{46-48}$ all-electron

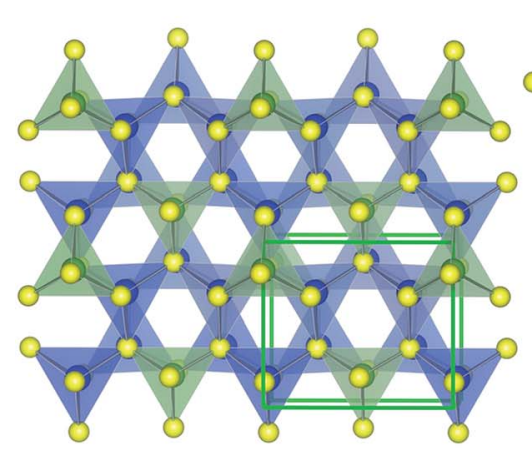

Enargite $\mathrm{Cu}_{3} \mathrm{AsS}_{4}$

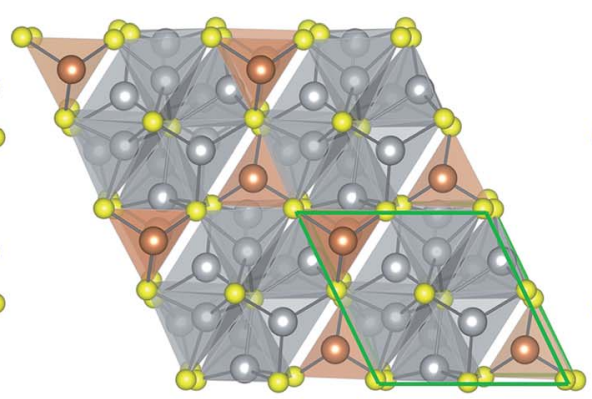

Stephanite $\mathrm{Ag}_{5} \mathrm{SbS}_{4}$

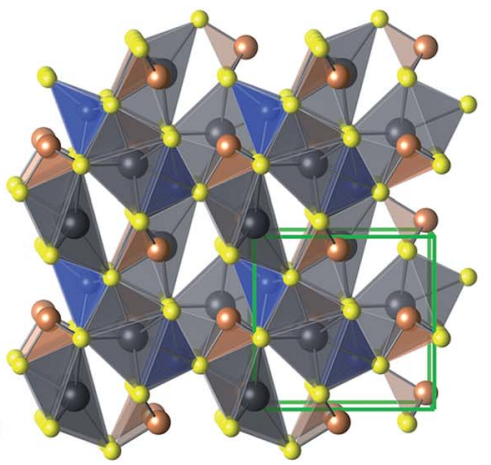

Bournonite CuPbSbS 3

Fig. 2 Illustrations of the crystal structures of candidate solar minerals: enargite (space group $P m n 2_{1}$ ), stephanite (space group $C m c 2_{1}$ ), and bournonite (space group $P m n 2_{1}$ ). 
electronic structure code, which is an implementation of density functional theory (DFT) based on numeric atomcentered orbital basis sets with a linear-scaling approach to hybrid functionals. ${ }^{\mathbf{4 9 , 5 0}}$ We use the short-range screened hybrid exchange-correlation HSE06 functional ${ }^{51}$ and spin-orbit coupling (SOC) ${ }^{52}$ is included. Hybrid DFT functionals have been found to correct for the underestimation of the optical band gap inherent in the generalized gradient and local density approximations..$^{53,54}$

The FHI-aims default 'tight' numerical settings are used for all calculations, which specifies the basis sets, integration grids, and Hartree potential. Structural optimization was performed with the Broyden-Fletcher-Goldfarb-Shanno algorithm. We fix the lattice parameters of the unit cell to room temperature X-ray diffraction data values from the Inorganic Crystal Structure Database (ICSD) ${ }^{55}$ and optimize the internal coordinates with a tolerance of $10^{-3} \mathrm{eV} \AA^{-1}$. A $\Gamma$-centred $4 \times 4 \times 4 k$-point grid is used to sample the electronic Brillouin zone for structural optimization, but a more dense $k$-point grid of $8 \times 8 \times 8$ was required for convergence for band structure calculations. Convergence tests for the calculation settings are given in the ESI. $\uparrow$ All visuals of atomic and electronic structure are produced using VESTA. ${ }^{56}$

\subsection{Carrier effective masses}

To assess the semiconducting potential of these materials, we obtain values for the carrier effective masses $\left(m^{*}\right)$ at the band extrema of the electronic band structures. We use a fitting procedure for the three independent components of the $m^{*}$ tensor for an orthorhombic crystal structure, shown in eqn (1), where the three components are in three directions parallel to crystallographic directions $a, b$ and $c(\|a\|$,$b and \| c)$, respectively.

$$
\frac{1}{m^{*}}=\frac{1}{\hbar^{2}}\left[\begin{array}{lll}
a & 0 & 0 \\
0 & b & 0 \\
0 & 0 & c
\end{array}\right]
$$

Once the location of the band extrema has been determined from our calculated electronic band structures, we recalculate the band structure over a restricted data range close to the band extrema along the three axes. We then obtain expressions for the three components of $m^{*}$ at the upper valence and lower conduction bands by numerical parabolic fits to the calculated restricted band structures within a fitting range of $k_{0} \pm 0.01$ bohr ${ }^{-1}$, using eqn (2), where $k_{0}$ denotes the location of the band extremum in $k$-space.

$$
E(k)=E_{0}+\frac{\hbar^{2}}{2 m^{*}}\left(k-k_{0}\right)^{2}
$$

\subsection{Optical response function}

The linear macroscopic dielectric tensor as a function of photon frequency, $\varepsilon^{i j}(\omega)$, of each material is calculated within the random phase approximation as implemented in FHI-aims, following the derivation in ref. 57 . We use this to predict the high-frequency dielectric response of the semiconductor to incident sunlight, i.e. the response of the electron density. Interand intra-band contributions to the dielectric function are computed, but the former dominate the optical spectra of semiconducting materials. Indirect (phonon assisted) transitions are not accounted for, and generally have weaker intensity, but may make a substantial contribution to the optical properties of materials with strongly indirect band structures.

A $k$-point grid of $8 \times 8 \times 8$ was required to reach convergence in the calculated dielectric function for bournonite $\left(\mathrm{CuPbSbS}_{3}\right)$, whereas a more dense $k$-point grid of $10 \times 10 \times 10$ was required for both enargite $\left(\mathrm{Cu}_{3} \mathrm{AsS}_{4}\right)$ and stephanite $\left(\mathrm{Ag}_{5} \mathrm{SbS}_{4}\right)$. Data for convergence tests are included in the ESI. $\dagger$

We obtain the frequency-dependent absorption coefficient in units of $\mathrm{cm}^{-1}$ for each material from the real and imaginary components of the dielectric function using eqn (3). The derivation for the units of the absorption coefficient is given in the ESI. $\dagger$

$$
\alpha(\omega)=\frac{4 \pi}{h c} \omega \sqrt{\frac{-\operatorname{Re} \varepsilon(\omega)+\sqrt{\operatorname{Re}^{2} \varepsilon(\omega)+\operatorname{Im}^{2} \varepsilon(\omega)}}{2}}
$$

\subsection{Spontaneous polarisation}

To investigate the strength of polarity, calculations of the spontaneous electric polarisation, $P_{\mathrm{s}}$, of each material were performed using the Berry-phase formalism ${ }^{58}$ with the methodology outlined in ref. 59. Only differences in polarisation are physically meaningful; we therefore optimise the structure with polarisation $+P_{\mathrm{s}}$ and invert this structure to get the opposite polarisation, $-P_{\mathrm{s}}$. The polarisation difference between those two structures, $2 P_{\mathrm{s}}$, is calculated. We verify that the change in polarisation is continuous by considering the polarisation for a number of configurations connecting the two structures, with their coordinates $\mathbf{r}$ obtained from eqn (4), where $\lambda$ is a number between 0 and 1 .

$$
\mathbf{r}=\lambda \mathbf{r}_{P_{\mathrm{s}}}+(1-\lambda) \mathbf{r}_{-P_{\mathrm{s}}}
$$

These calculations were performed in $\operatorname{VASP}^{60,61}$ using the HSE06 functional, ${ }^{51}$ projector augmented wave core potentials ${ }^{62}$ and a $500 \mathrm{eV}$ plane wave cutoff energy, without including SOC. Sampling of the electronic Brillouin zone using a $2 \times 2 \times 2$ grid of $k$-points was found to be converged with respect to the calculated polarisation values. Further details of the polarisation calculations are included in the ESI. $\dagger$

\section{Results and discussion}

In the following sections we assess the predicted optoelectronic properties of each material in turn. As discussed in the introduction, an effective PV material must absorb light and transport charge. In addition to the band gap and carrier effective masses, we consider the dielectric function, and the associated optical absorption spectra. We finish with an assessment of 
spontaneous electric polarisation to determine the strength of the polarity in the materials and the effect on the electronic band structure.

\subsection{Enargite $\left(\mathrm{Cu}_{3} \mathrm{AsS}_{4}\right)$}

The potential of the sulfosalt mineral enargite $\left(\mathrm{Cu}_{3} \mathrm{AsS}_{4}\right)$ for PV applications was suggested by Pauporté and Lincot in $1995 .^{42} \mathrm{It}$ received little scientific interest until $\mathrm{Yu}$ and Zunger's highthroughput study based on their SLME metric, where they calculate a theoretical power conversion efficiency of $25.5 \%$ for the material. ${ }^{4}$ A recent experimental work has emerged assessing the photovoltaic response of six minerals, including enargite. ${ }^{40}$

The crystallographic unit cell (as shown in Fig. 2) has orthorhombic symmetry with space group $P m n 2_{1}$ and tetrahedral coordination for all atoms. ${ }^{63}$ It has recently been proposed that tetrahedrally bonded multinary semiconductors may be more prone to cation disorder, and the associated extended antisite defect pairs, than lower dimensional multinary compounds. ${ }^{64}$ However, compared to materials such as $\mathrm{Cu}_{2}$ $\mathrm{ZnSn}(\mathrm{S}, \mathrm{Se})_{4}$ that are known to suffer from mixing of $\mathrm{Cu}$ and $\mathrm{Zn}$ cations, ${ }^{65-67}$ the cations in enargite are more dissimilar in terms of charge and radius. It has been shown that replacing cations with species further apart on the periodic table can reduce this type of disorder. ${ }^{68-71}$ We therefore expect cation disorder to be reduced in this compound, as has been found to be the case when substituting $\mathrm{Cu}$ with $\mathrm{Ag}^{70}$ or $\mathrm{Zn}$ with $\mathrm{Ba}^{\mathbf{6 8 , 6 9}}$ in $\mathrm{Cu}_{2} \mathrm{ZnSn}(\mathrm{S}, \mathrm{Se})_{4}$.

Enargite is a mineral semiconductor of type $\mathrm{A}_{3}^{\mathrm{I}} \mathrm{B}^{\mathrm{V}} \mathrm{C}_{4}^{\mathrm{II}}$. Natural samples of enargite are frequently found as an impurity in copper ores. ${ }^{72}$ Natural samples have been found to exhibit the electrical properties of a p-type doped semiconductor with a conductivity of $0.0014 \mathrm{~S} \mathrm{~m}^{-1}$ (from the stated value of approximately $7 \Omega \mathrm{cm}$ for the resistivity at $295 \mathrm{~K}){ }^{42}$ The main impurities in natural enargite are $\mathrm{Sb}$ and $\mathrm{Fe}$, but $\mathrm{Pb}$ and $\mathrm{Ag}$ are also known to be present. ${ }^{72}$ In a recent study on natural sulfide minerals, ${ }^{40}$ the authors detected $<1 \%$ of $\mathrm{Sb}$ impurities in the natural samples of enargite, which show a clear p-type photoconductivity. The p-type response could either be due to intrinsic acceptor defects or due to defects introduced by the $\mathrm{Sb}$ impurities. In 1995, Pauporté and Lincot measured two optical transitions in enargite: an indirect one at $1.19 \mathrm{eV}$ and a direct one at $1.44 \mathrm{eV}$. However more recent studies have reported values of $1.28 \mathrm{eV}$ (ref. 41) and $1.36 \mathrm{eV}$ (ref. 40) for a direct band gap, with some photocurrent due to band tailing further in the IR region for the latter, which the authors attribute to lattice disorder or impurity states in the band gap. $G_{0} W_{0}$ calculations based on wavefunctions generated from the hybrid functional HSE06 (ref. 51) predicted a value of $1.32 \mathrm{eV}$ for the band gap. ${ }^{73}$ Although a number of different values have been reported for the band gap of enargite, all values fit within the optimal range for a solar absorber material. ${ }^{20}$

4.1.1 Enargite: electronic structure. The chemical formula $\mathrm{Cu}_{3} \mathrm{AsS}_{4}$ suggests the presence of closed-shell $\mathrm{Cu}(\mathrm{I})$ and $\mathrm{As}(\mathrm{v})$ ions. It has been proposed that a number of the beneficial properties of lead halide perovskites are linked to the presence of lone pairs of electrons and that other materials with posttransition metals with an $n \mathrm{~s}^{2}$ electronic configuration may also exhibit similar properties. ${ }^{21}$ While As(III) has a $4 \mathrm{~s}^{2}$ electronic configuration, for As(v) as present here, the s orbitals are formally empty. We have further confirmed the charge state as As(v) using electron localisation functions (ELFs) ${ }^{75}$ calculated with VASP; however, we note the complications of assigning oxidation states from first principles. ${ }^{76}$ The ELF gives the probability of finding an electron near a reference electron, and thus highlights the presence of bonds and lone pairs; further details are given in the ESI. $\dagger$

For enargite, we predict a direct band gap at the $\Gamma$ point with a magnitude of $1.24 \mathrm{eV}$, which is close to the reported $G_{0} W_{0} @$ HSE06 value of $1.32 \mathrm{eV} .^{73}$ The calculated band structure is shown in Fig. 3a. The conduction band minimum (CBM) is dispersive, indicating the potential for high carrier mobility at the band edge. This is confirmed by the estimates for the minority carrier effective masses of electrons in the conduction band, $m_{\mathrm{c}}$, presented in Table 1 , which also indicates that the effective masses from $I \rightarrow X, Y, Z$ are almost isotropic. However, the estimated values for effective masses in Table 1 indicate that holes are heavier along the $\Gamma \rightarrow Y, Z$ directions in enargite.

It has been suggested for other semiconducting materials that the defect-tolerance of optoelectronic properties, to a certain extent, can be associated with an electronic structure where the VBM possesses predominantly antibonding character. ${ }^{12,77,78} \mathrm{CuInSe}_{2}$ is an example of another thin-film PV technology that is defect tolerant with shallow defects ${ }^{78}$ and benign grain boundaries. ${ }^{79,80}$ The electronic density of states (DOS) at the top of the valence band in enargite, which is shown in Fig. 4, shares some common features with that of CuInSe $\mathrm{C}_{2}$. In the case of $\mathrm{CuInSe}_{2}$ the upper valence bands consist of the hybridized $\mathrm{Cu}$ d-states and Se p-states, whereas for enargite it is instead $\mathrm{S}$ p-states hybridized with $\mathrm{Cu}$ d-states. The $\mathrm{p}-\mathrm{d}$ repulsion is large in CuInSe ${ }_{2}$ and appears to be even larger in enargite. In $\mathrm{CuInSe}_{2}$, the $\mathrm{p}-\mathrm{d}$ repulsion gap separates the bonding $\mathrm{p}-\mathrm{d}$ states below and the antibonding $\mathrm{p}-\mathrm{d}$ states above, yielding antibonding states for the upper valence bands.

To assess further if enargite possesses an upper valence band with antibonding character we visualize the electron

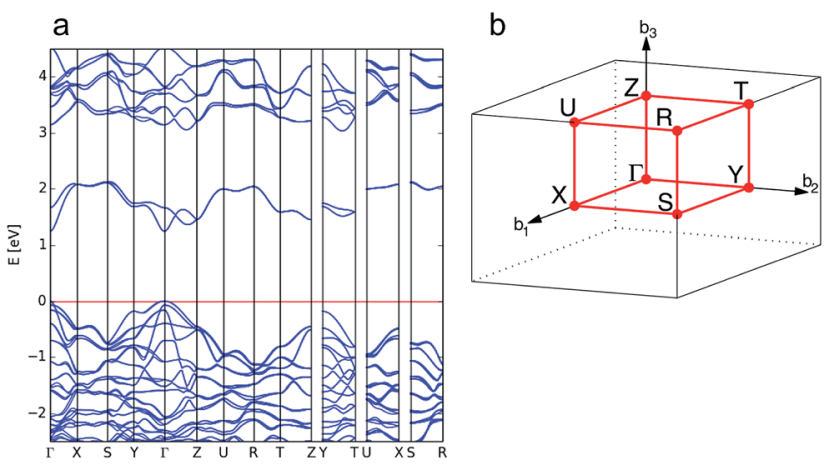

Fig. 3 Calculated electronic band structure of enargite $\left(\mathrm{Cu}_{3} \mathrm{AsS}_{4}\right)$ (a) and the reciprocal space $k$-path for the structure determined by the Aflow-online utility ${ }^{74}$ (b). 
Table 1 Effective masses of electrons at the conduction band minimum, $m_{c}$, and holes at the valence band maximum, $m_{h}$, of enargite $\left(\mathrm{Cu}_{3} \mathrm{AsS}_{4}\right)$, stephanite $\left(\mathrm{Ag}_{5} \mathrm{SbS}_{4}\right)$ and bournonite $\left(\mathrm{CuPbSbS}_{3}\right)$ in units of the free electron mass $m_{\mathrm{e}}$, determined by parabolic fits to the calculated band structures at the band extrema. The optical dielectric constants, $\varepsilon_{\infty}$, calculated within the random phase approximation are also reported

\begin{tabular}{|c|c|c|c|c|c|c|c|c|c|c|c|c|c|c|}
\hline \multicolumn{5}{|c|}{ Enargite $\left(\mathrm{Cu}_{3} \mathrm{AsS}_{4}\right)$} & \multicolumn{5}{|c|}{ Stephanite $\left(\mathrm{Ag}_{5} \mathrm{SbS}_{4}\right)$} & \multicolumn{5}{|c|}{ Bournonite $\left(\mathrm{CuPbSbS}_{3}\right)$} \\
\hline Direction & $m_{\mathrm{e}}$ & $m_{\mathrm{h}}$ & $\varepsilon$ & & Direction & $m_{\mathrm{e}}$ & $m_{\mathrm{h}}$ & $\varepsilon$ & & Direction & $m_{\mathrm{e}}$ & $m_{\mathrm{h}}$ & $\varepsilon$ & \\
\hline$\| b$ & 0.23 & 1.20 & $\varepsilon_{\infty} y y$ & 5.89 & $\| b$ & 0.40 & 1.94 & $\varepsilon_{\infty}^{y y}$ & 5.86 & $\| b$ & 0.37 & 0.97 & $\varepsilon_{\infty}^{y y}$ & 7.24 \\
\hline$\| c$ & 0.22 & 1.35 & $\varepsilon_{\infty}^{z z}$ & 5.91 & $\| c$ & 0.26 & 0.77 & $\varepsilon_{\infty}^{z z}$ & 5.83 & $\| c$ & 0.50 & 0.86 & $\varepsilon_{\infty}^{z z}$ & 7.55 \\
\hline
\end{tabular}

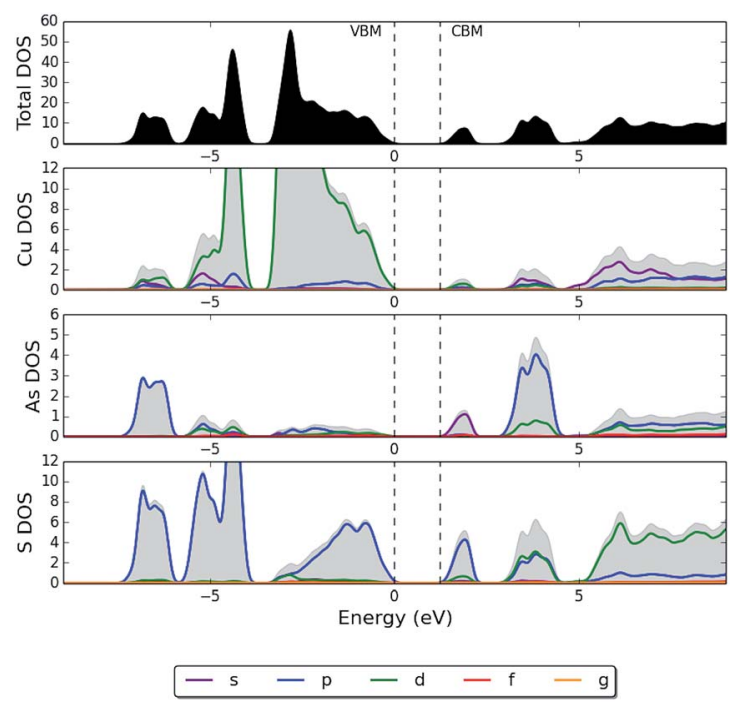

Fig. 4 HSEO6 + SOC partial electronic density of states (pDOS) of enargite $\left(\mathrm{Cu}_{3} \mathrm{AsS}_{4}\right)$, where the top of the valence band has been set to $0 \mathrm{eV}$.

wavefunction of the highest occupied state, as is shown in Fig. 5a. From this, the opposite parity of neighbouring $S$ p-orbitals and $\mathrm{Cu}$ d-orbitals indicates antibonding character at the valence band maximum, which could suggest that acceptor defects are more likely to produce shallow defect levels with respect to the band edges. Enargite may therefore have defecttolerant optoelectronic properties, which has been suggested in some recent studies. Firstly, the photocurrent conversion efficiency of a natural enargite sample was found to be greater than that of a natural kesterite sample. ${ }^{40}$ Secondly, the photocurrent density measured for enargite nanocrystals had a 10fold improvement to that of $\mathrm{Cu}_{3} \mathrm{SbS}_{4}$ nanocrystals, ${ }^{81}$ both of which could be expected to possess highly-defective nanocrystalline structures.

4.1.2 Enargite: optical properties. The optical properties of enargite are anisotropic, with the $x x, y y$ and $z z$ components of the optical dielectric tensor, $\varepsilon^{i j}(\omega)$, differing considerably, as shown in Fig. 6. We predict values of just under 6 for the static limit $(\omega \rightarrow 0)$ of the optical dielectric constants $\varepsilon_{\infty}^{i j}$ (given in Table 1), obtained from the $y$-intercept of the real components of $\varepsilon^{i j}(\omega)$. This is very similar to values of $\varepsilon_{\infty}{ }^{i j}$ calculated for the perovskite $\mathrm{MAPbI}_{3}$ of approximately 5.6 to $6.5{ }^{83}$

In Fig. 7 we plot the isotropic average of the optical absorption coefficient, $\alpha(\omega)$, of enargite, with comparison to GaAs and $\mathrm{MAPbI}_{3}$, as known strong PV absorber materials, and crystalline Si (c-Si) as a material that is known to have weak absorption. Enargite has a comparable strength of absorption to the strong absorber materials GaAs and $\mathrm{MAPbI}_{3}$, and considerably stronger than c-Si, within the region for the onset of absorption (incident photon energy of approximately $\omega=1-3 \mathrm{eV}$ ).

\subsection{Stephanite $\left(\mathrm{Ag}_{5} \mathrm{SbS}_{4}\right)$}

The unit cell of the second candidate, stephanite $\left(\mathrm{Ag}_{5} \mathrm{SbS}_{4}\right)$, also has an orthorhombic crystal structure but with space group $\mathrm{Cmc2}_{1}$ (Fig. 2). The chemical formula suggests formal
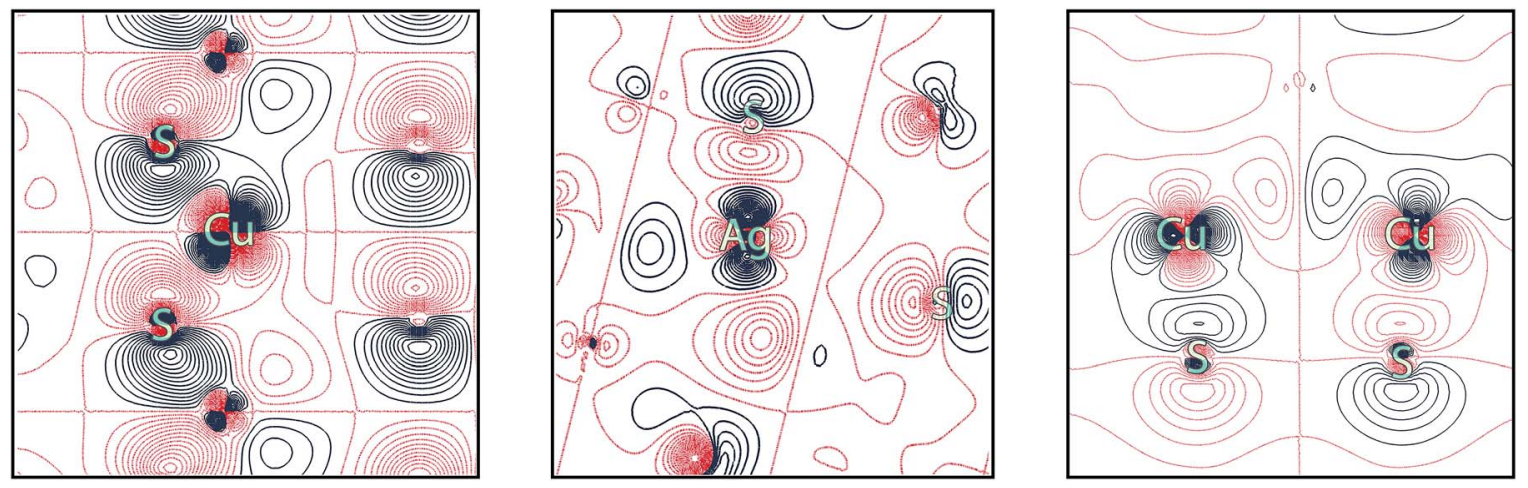

Fig. 5 The real component of the electron wavefunction of the highest occupied state in (left panel) enargite $\left(\mathrm{Cu}_{3} \mathrm{As} \mathrm{S}_{4}\right)$, (centre panel) stephanite $\left(\mathrm{Ag}_{5} \mathrm{SbS}_{4}\right)$ and (right panel) bournonite $\left(\mathrm{CuPbSbS}_{3}\right)$, showing sulfur $\mathrm{p}$-orbitals and copper $\mathrm{d}$-orbital in enargite and bournonite and silver d-orbitals in stephanite. The difference in colour indicates the different parity of the wavefunctions and the position of the ions are indicated on the plot. 


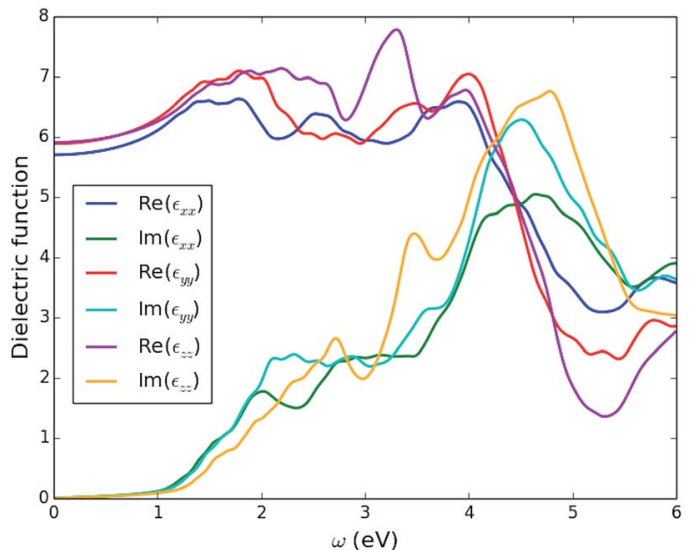

Fig. 6 Three independent components of the calculated optical dielectric tensor, $\varepsilon(\omega)$, as a function of incident photon energy, $\omega$, for enargite $\left(\mathrm{Cu}_{3} \mathrm{AsS}_{4}\right)$.

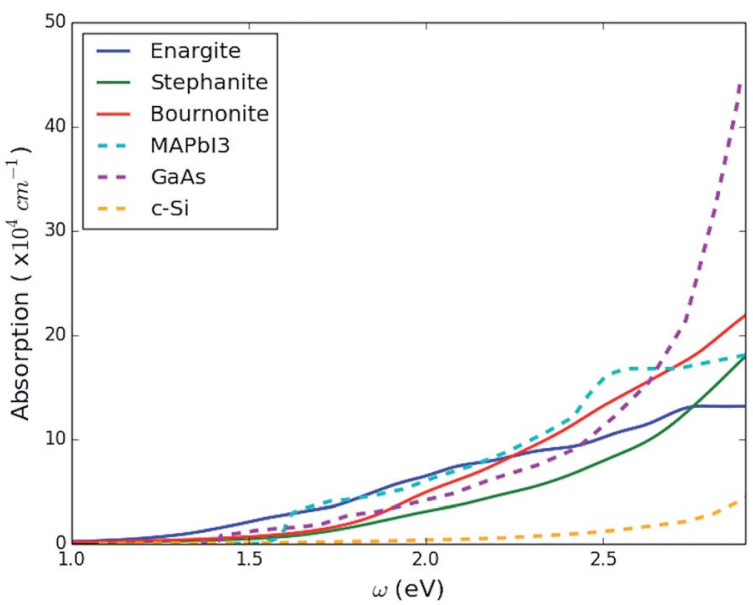

Fig. 7 Isotropic average of the optical absorption coefficient for three sulfosalt materials enargite $\left(\mathrm{Cu}_{3} \mathrm{AsS}_{4}\right)$, stephanite $\left(\mathrm{Ag}_{5} \mathrm{SbS}_{4}\right)$ and bournonite $\left(\mathrm{CuPbSbS}_{3}\right)$ plotted in comparison to the same parameter for other important photovoltaic materials over the onset energy range $(1-3 \mathrm{eV})$. The comparison photovoltaic materials include: the strong direct-gap absorber material GaAs, the weaker indirect-gap absorber crystalline-Si and the hybrid perovskite $\mathrm{MAPbl}_{3}$, where data for these latter compounds was taken from ref. 82.

oxidations states of $\mathrm{Ag}(\mathrm{I})$ and $\mathrm{Sb}(\mathrm{III})$, which are associated with $4 \mathrm{~d}^{10}$ and $5 \mathrm{~s}^{2}$ valence electronic configurations. The structure consists of $\mathrm{SbS}_{3}$ trigonal pyramids layered along the $c$-axis that are connected with Ag atoms that form triangular and near tetrahedral structures with $\mathrm{S}$ atoms. ${ }^{40}$ As was discussed for enargite, the components in stephanite are dissimilar in terms of charge and size, so it could be expected that cation disorder will not be prevalent in this compound.

There is limited literature on the optical or electrical properties of stephanite apart from a work in 1973 (ref. 43) showing the electrical resistivity of a synthetic sample of stephanite as a function of temperature. They report a resistivity of approximately $9 \Omega \mathrm{cm}$ at $110{ }^{\circ} \mathrm{C}$, which corresponds to a conductivity of $0.0011 \mathrm{~S} \mathrm{~m}^{-1}$. It has been reported that stephanite has a band gap of $1.62 \mathrm{eV}$ (ref. 41) and a recent study on a natural sample of stephanite has measured a band gap of $1.67 \mathrm{eV}$ and p-type conductivity. ${ }^{40}$ Chemical analysis indicated that there was no detectable level of impurities present. ${ }^{40}$ This could suggest that the p-type conductivity of the crystal is due to the presence of acceptor intrinsic defects in stephanite $\left(\right.$ e.g. $\left.\mathrm{V}_{\mathrm{Ag}}{ }^{-}\right)$. The work ${ }^{40}$ also comments on the possibility of high Ag ion conductivity. Ion transport has been suggested as a cause of current-voltage hysteresis in lead halide perovskites; ${ }^{84}$ but it can also contribute to 'self-healing' of detrimental extended defects as ions can redistribute over time.

There has been some speculation in the literature on the possibility of ferroelectric behaviour in stephanite due to the presence of polar phases at low temperatures in pyrargyrite $\left(\mathrm{Ag}_{3} \mathrm{SbS}_{3}\right)$, proustite $\left(\mathrm{Ag}_{3} \mathrm{AsS}_{3}\right)$, and stibnite $\left(\mathrm{Sb}_{2} \mathrm{~S}_{3}\right)$, which are crystallochemically related to stephanite. ${ }^{85}$ The same study notes that similar displacive structural changes occur in stephanite to those in proustite and pyrargyrite that are responsible for the ferroelectric properties.

4.2.1 Stephanite: electronic structure. For stephanite, we predict a direct band gap of $1.59 \mathrm{eV}$ at the $\Gamma$ point of the Brillouin zone, which is in good agreement with the literature experimental values. ${ }^{40,41}$ Similar to enargite, Fig. 8 a shows that the dispersion of the lower conduction band is greater than the upper valence band; this is reflected in the effective masses calculated for electrons and holes, shown in Table 1. The electronic pDOS of stephanite (Fig. 9) indicates that the valence band is mainly composed of hybridized $\mathrm{Ag}$ d-states and $\mathrm{S} \mathrm{p}$ states, while contributions from $\mathrm{Sb}$ s-states only appear at higher binding energy. In Fig. 5b we visualize the electron wavefunction of the highest occupied state in stephanite, which again displays anti-bonding character between the $\mathrm{Ag} \mathrm{d}$ and neighbouring $\mathrm{S} \mathrm{p}$.

4.2.2 Stephanite: optical properties. The optical properties of stephanite, as shown in Fig. 10, are more isotropic than those of enargite. This could be due to the crystal structure of enargite more closely resembling stacked two-dimensional planes than that of stephanite. The value of the optical dielectric constant for stephanite is similar to enargite, at just under 6 (Table 1). The strength in the onset of absorption predicted for stephanite

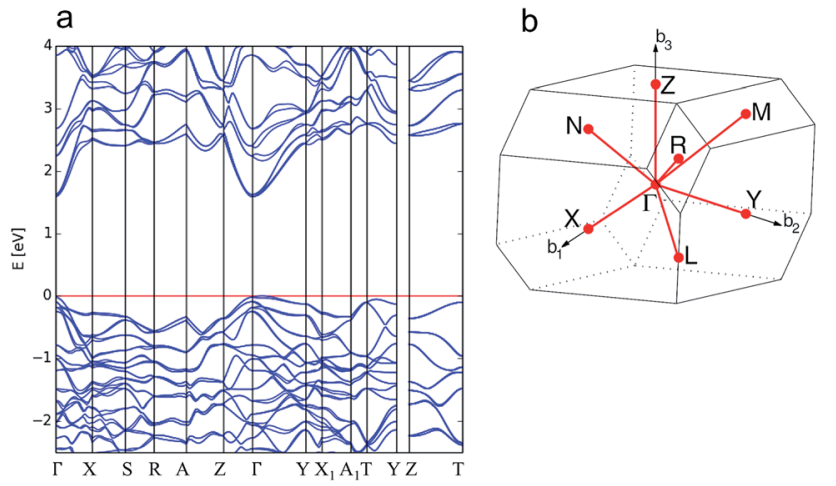

Fig. 8 Calculated electronic band structure of stephanite $\left(\mathrm{Ag}_{5} \mathrm{SbS}_{4}\right)(\mathrm{a})$ and the reciprocal space $k$-path for the structure determined by the Aflow-online utility ${ }^{74}(b)$. 


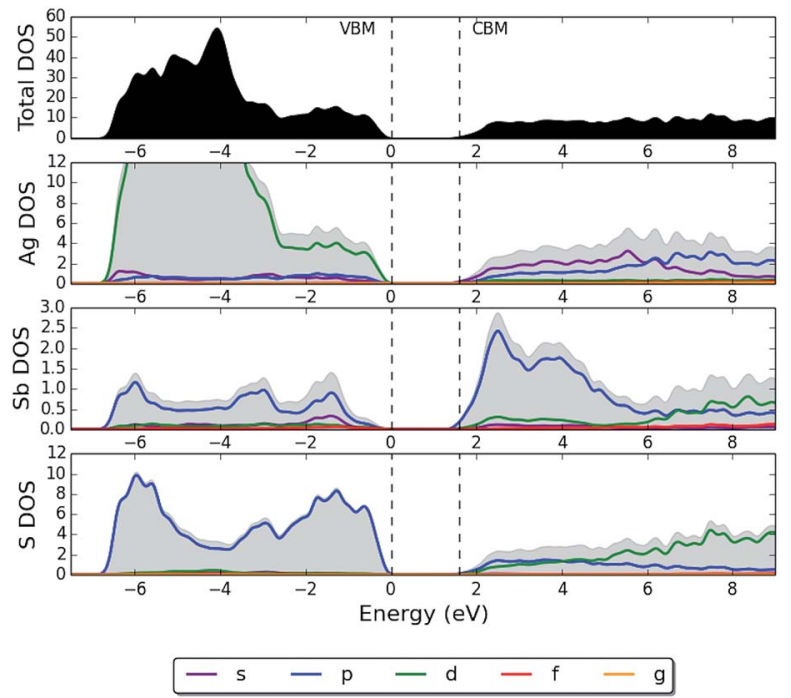

Fig. 9 HSEO6 + SOC partial electronic density of states (pDOS) of stephanite $\left(\mathrm{Ag}_{5} \mathrm{SbS}_{4}\right)$, where the top of the valence band has been set to $0 \mathrm{eV}$.

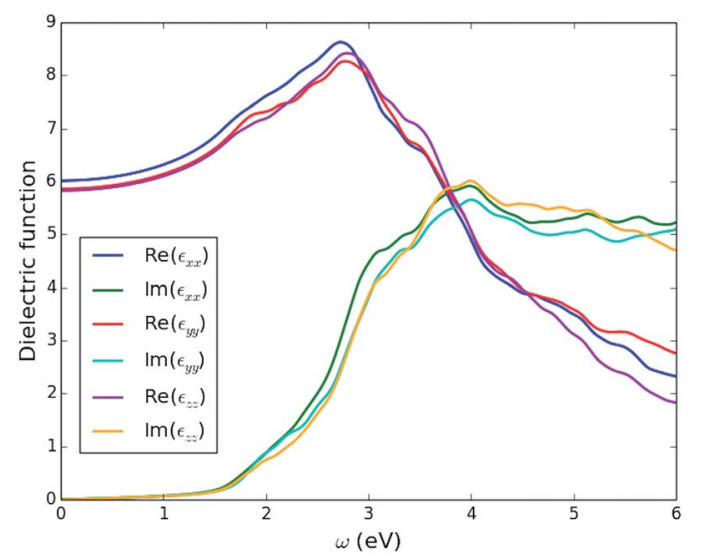

Fig. 10 Three components of the calculated dielectric function, $\varepsilon(\omega)$, as a function of incident photon energy, $\omega$, for stephanite $\left(\mathrm{Ag}_{5} \mathrm{SbS}_{4}\right)$.

shown in Fig. 7 is less than that of the high-performance absorbers GaAs and $\mathrm{MAPbI}_{3}$, but still considerably stronger than that of crystalline Si.

\subsection{Bournonite ( $\left.\mathrm{CuPbSbS}_{3}\right)$}

Bournonite $\left(\mathrm{CuPbSbS}_{3}\right)$ again adopts an orthorhombic crystal structure and the same space group as enargite, $P m n 2_{1}$. The unit cell of bournonite is shown in Fig. 2. The structure is derived from stibnite $\left(\mathrm{Sb}_{2} \mathrm{~S}_{3}\right)$, where $\mathrm{Pb}(\mathrm{II})$ atoms alternatively occupy the $\mathrm{Sb}(\mathrm{III})$ sites and $\mathrm{Cu}(\mathrm{I})$ atoms form tetrahedra to compensate for the charge. ${ }^{40}$

Measured values of $1.23 \mathrm{eV}$ (ref. 41) and $1.31 \mathrm{eV}$ (ref. 86) have been reported for the band gap, which are both within the optimal range for a solar absorber material. Recently, this material has received increasing scientific interest for thermoelectric and rewriteable data storage applications due to a low thermal conductivity, which has been attributed to the distorted environments of the $\mathrm{Pb}$ (II) and $\mathrm{Sb}$ (III) atoms from the stereochemically active lone-pair $\mathrm{s}^{2}$ electrons. ${ }^{44}$ Consequently, works on the synthesis of bournonite are beginning to emerge. ${ }^{86} \mathrm{~A}$ study of two natural samples of bournonite ${ }^{40}$ reported n-type conductivity, a direct gap of $1.29 \mathrm{eV}$, and an indirect band gap of $1.17 \mathrm{eV}$ in one sample, and the same direct band gap and a lower indirect band gap of $1.01 \mathrm{eV}$ in another.

4.3.1 Bournonite: electronic structure. For bournonite, we predict an indirect band gap in the $\Gamma-Y$ direction with a magnitude of $1.37 \mathrm{eV}$ and the smallest direct gap is predicted to be only slightly larger at $1.41 \mathrm{eV}$. The indirect gap is in quite good agreement with experimental values. ${ }^{41,86}$ The conduction band minimum features a spin splitting due to SOC, which can be seen from comparing the plots of results before and after the inclusion of SOC along the $T-Y$, shown in Fig. 11a. The effective masses at the conduction band of bournonite (Table 1) are not as light or isotropic as in enargite; however, both the hole and electron masses remain below $1 m_{\mathrm{e}}$.

The upper valence band of bournonite is formed primarily of hybridized $\mathrm{Cu}$ d-states and S p-states (Fig. 12), although there does not appear to be a pronounced $\mathrm{p}-\mathrm{d}$ repulsion as was shown in the pDOS plot for enargite. Contributions from $\mathrm{Sb}$ and $\mathrm{Pb} \mathrm{s}-$ states at the VBM appear to be minor. In Fig. $5 \mathrm{c}$ we visualize the electron wavefunction of the highest occupied state in bournonite to determine the bonding characteristics. As for the previous two materials, the opposite parity of the electron wavefunctions for the anion and cation show antibonding character, which could support defect tolerance.

4.3.2 Bournonite: optical properties. The optical properties of the final candidate absorber material (Fig. 13) are more anisotropic than stephanite but less than enargite. The optical dielectric constant (7.1-7.6) of bournonite is larger than that of enargite and stephanite (5.7-6.0). The larger value could be due to the presence of the $\mathrm{Pb}$ ion in bournonite, which is larger and more polarisable than the cations in enargite and stephanite. Again bournonite has a comparable onset of absorption to that of established PV absorber materials (see Fig. 7).

\subsection{Polarisation and Rashba splitting}

The results presented above have shown the three candidate materials have electronic and optical properties suitable for a

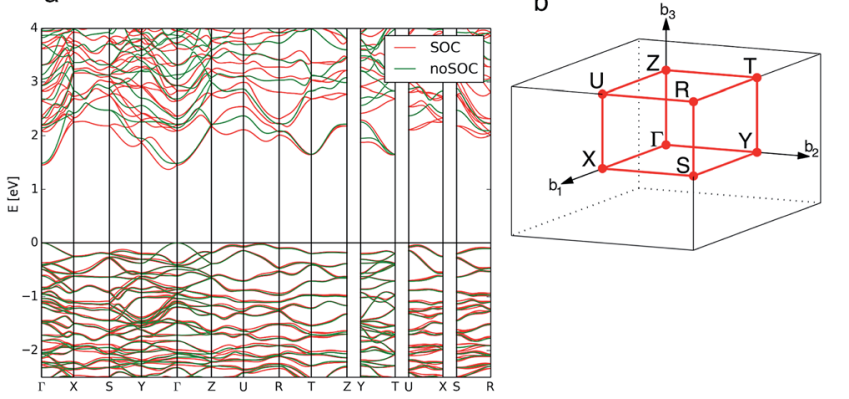

Fig. 11 Calculated band structure of bournonite $\left(\mathrm{CuPbSbS}_{3}\right)$ showing the result without the inclusion of spin-orbit coupling (SOC) in green and the calculation including SOC in red (a) and the reciprocal space $k$ path for the structure determined by the Aflow-online utility ${ }^{74}(b)$. 


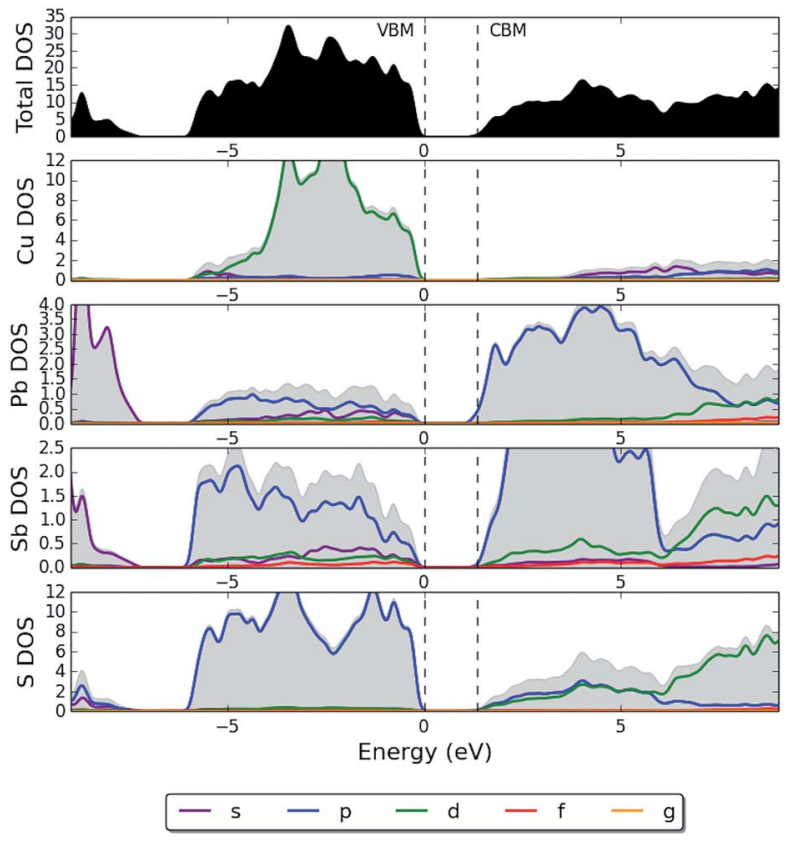

Fig. 12 HSEO6 + SOC partial electronic density of states (pDOS) of bournonite $\left(\mathrm{CuPbSbS}_{3}\right)$, where the top of the valence band has been set to $0 \mathrm{eV}$.

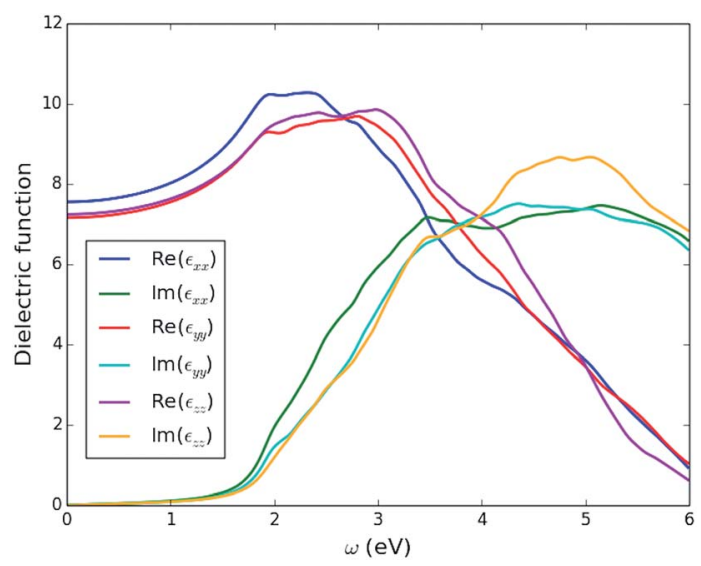

Fig. 13 Three components of the calculated dielectric function, $\varepsilon(\omega)$, as a function of incident photon energy, $\omega$, for bournonite $\left(\mathrm{CuPbSbS}_{3}\right)$.

solar energy harvesting. An additional criterion for our search is that the materials adopt a polar space group.

4.4.1 Lattice polarisation. We have quantified the strength of polarity within the modern theory of polarisation. Spontaneous polarisations of $67.8,31.9$ and $1.83 \mu \mathrm{C} \mathrm{cm}^{-2}$ are found in enargite, stephanite and bournonite, respectively (see Fig. 14). Table 2 also shows the values of spontaneous polarisation calculated for the materials in this study, along with measured and some calculated values for known ferroelectric materials. Whether a material will exhibit the ferroelectric-photovoltaic phenomena outlined in Section 2.2 is dependent upon a large number of factors, which are discussed in ref. 87. One parameter however is the magnitude of the polarisation ${ }^{88}$ and we show here that the calculated spontaneous polarisation for both enargite and stephanite is high and comparable to those of standard ferroelectric materials $\mathrm{BaTiO}_{3}$ and $\mathrm{PbTiO}_{3}$.

It is worth noting that for the materials in this study the switching from one polarisation to the other requires a significant rearrangement of the atoms. We estimate the switching barrier from the energy change along the paths used to calculate the spontaneous lattice polarisation, but note that this estimate is an upper limit for the switching barrier as the intermediate structures have not been relaxed to their minimum energy configuration (further details included in the ESI $\dagger$ ). We estimate the upper limit for the switching barrier to be 19.7, 12.5 and $21.8 \mathrm{eV}$ per unit cell for enargite, stephanite and bournonite; which are orders of magnitude larger than barriers calculated for $\mathrm{BaTiO}_{3}{ }^{89}$ Thus, the direction of polarisation of the materials is unlikely to be easy to switch, making them unsuitable for switchable memory applications. However, the local electric fields could still be beneficial for enhanced charge separation in solar energy applications.

4.4.2 Relativistic Rashba splitting. The presence of macroscopic polarisation may have a direct effect on the transport and collection of photogenerated charge carriers in the direction of the associated internal electric field. There is an additional effect on the electronic structure: the combination of heavy elements with non-centrosymmetric crystal structures leads to a relativistic spin-splitting of the bands. For cases where the orbital components of the valence and conduction bands are different, the so-called Rashba/Dresselhaus splitting can turn a direct band material indirect. This was shown to be the case for bournonite in Fig. 11. This effect has been associated with slow electron-hole recombination in lead halide perovskites. ${ }^{93-95}$

The spin-orbit interaction varies with the square of the atomic mass, yielding an expected splitting size ordering of $\mathrm{Pb}$ $\gg \mathrm{Sb}>\mathrm{As}$; however, this is also influenced by the local electric field around the metal centre. From our calculations, we predict

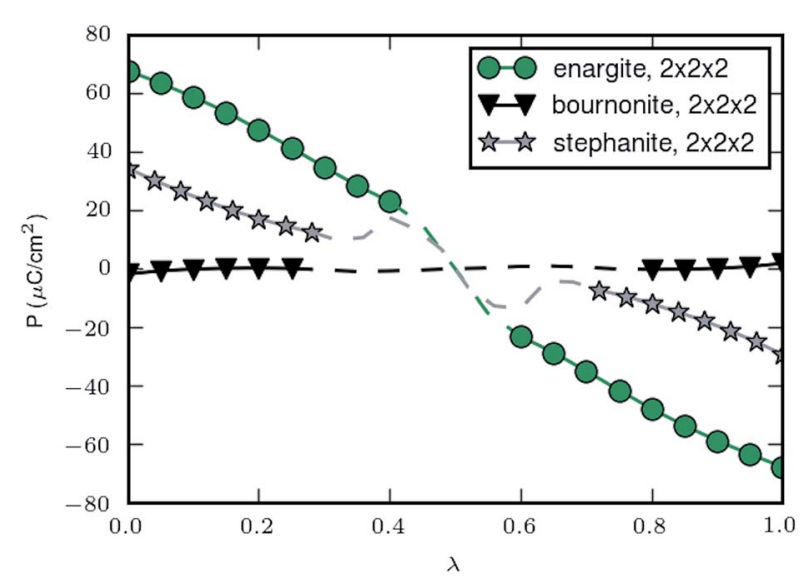

Fig. 14 Spontaneous polarisation along a path connecting the structures with $+P_{\mathrm{s}}$ and $-P_{\mathrm{s}}$ for enargite $\left(\mathrm{Cu}_{3} \mathrm{AsS}_{4}\right)$, stephanite $\left(\mathrm{Ag}_{5} \mathrm{SbS}_{4}\right)$ and bournonite $\left(\mathrm{CuPbSbS}_{3}\right)$. The markers indicate points calculated with $2 \times 2 \times 2 \mathrm{k}$-points and the dashed line is the path obtained using $1 \times 1 \times 1 k$-points. The curves are set to pass through 0 for $\lambda=0.5$. See ESI† for further details. 
Table 2 Calculated spontaneous polarisation for enargite $\left(\mathrm{Cu}_{3} \mathrm{AsS}_{4}\right)$, stephanite $\left(\mathrm{Ag}_{5} \mathrm{SbS}_{4}\right)$ and bournonite $\left(\mathrm{CuPbSbS}_{3}\right)$ compared to values of known ferroelectric crystals

\begin{tabular}{llll}
\hline & Method & Ref. & $P_{\mathrm{s}}\left(\mu \mathrm{C} \mathrm{cm}{ }^{-2}\right)$ \\
\hline Enargite & DFT (HSE06) & This work & 67.8 \\
Stephanite & DFT (HSE06) & This work & 31.9 \\
Bournonite & DFT (HSE06) & This work & 1.83 \\
$\mathrm{BaTiO}_{3}$ & DFT (HSE06) & 90 & 40.7 \\
$\mathrm{BaTiO}_{3}$ & Expt. & 91 & 26 \\
$\mathrm{PbTiO}_{3}$ & DFT (LDA) & 92 & 88 \\
$\mathrm{PbTiO}_{3}$ & Expt. & 91 & 57 \\
$\mathrm{SbSI}$ & Expt. & 91 & 25
\end{tabular}

that only bournonite will exhibit Rashba splitting, despite the considerably weaker spontaneous polarisation we predict for this material. Bournonite is the only one of the three material that contains $\mathrm{Pb}$, which suggests that the atomic mass of the heavy element is the more dominant factor than the strength of spontaneous polarisation for the Rashba effect. The splitting needs to be sufficient so that for a given temperature and light intensity that the Rashba pockets are partially filled; above this threshold direct band gap behaviour is recovered. For bournonite, we measure an energy difference in the CBM between direct and indirect recombination of approximately $80 \mathrm{meV}$, whereas $k_{\mathrm{B}} T$ at typical solar cell operating temperature of $50{ }^{\circ} \mathrm{C}$ is $28 \mathrm{meV}$, indicating that this indirect behaviour should play a role in an operating solar cell.

\section{Conclusions and outlook}

We have used a first-principles quantum mechanical approach to assess the optoelectronic properties of the three candidate photoferroic materials: enargite $\left(\mathrm{Cu}_{3} \mathrm{AsS}_{4}\right)$, stephanite $\left(\mathrm{Ag}_{5} \mathrm{SbS}_{4}\right)$ and bournonite $\left(\mathrm{CuPbSbS}_{3}\right)$. We predicted a direct band gap of $1.24 \mathrm{eV}$, a direct band gap of $1.59 \mathrm{eV}$ and a slightly indirect band gap of $1.37 \mathrm{eV}$ for enargite, stephanite and bournonite respectively, within the optimal range for a single junction solar cell. We also observe similar features (spin-orbit splitting) in the band structure of bournonite to those associated with the highperformance of hybrid perovskites. ${ }^{93}$ We predict low electron effective masses for all three materials and heavier holes (see Table 1). We also predict optical dielectric constants, $\varepsilon_{\infty}$, again comparable to hybrid perovskites. ${ }^{83}$

We have calculated the spontaneous polarisation density for all three materials and from this we predict that enargite and stephanite will have considerable spontaneous polarisations, comparable to that of standard ferroelectric materials $\mathrm{BaTiO}_{3}$ and $\mathrm{PbTiO}_{3}$. This could suggest that it may be possible to combine a near-optimal band gap (for AM1.5 solar radiation) with ferroelectric-photovoltaic phenomena such as the bulk photovoltaic effect or anomalous photovoltaic effect within these materials. With the upper limit for the power conversion efficiency from these novel PV phenomena still being an open question, these materials could allow for new routes to high efficiency devices.
Our study has shown that the three minerals merit deeper investigation. In addition to further experimental work on synthesis, characterisation and optimisation, the extension of theoretical investigations to include analysis of the defect tolerance of the bulk (beyond the speculation made in this study based on the bonding character of the VBM), and identifying compatible interfaces for high-efficiency devices could help to accelerate the development of these new technologies.

\section{Data access statement}

The optimised crystal structures of the three minerals studied are available at https://github.com/wmd-group/crystal_structures. The input and output files for the DFT calculations are available from the online repository NOMAD at http://dx.doi.org/10.17172/ nomad/2017.05.16-1.

\section{Acknowledgements}

This work has been supported by the EPSRC grant no. EP/ L016354/1 and EP/K016288/1 (SKW) and by the ERC programme grant no. 277757 (KLS). Part of this work was also supported by the National Science Foundation under Grant No. 1511737 (WPH, TZ, DBM, VB). AW is supported by a Royal Society University Research Fellowship. This work benefited from access to ARCHER, the UK's national high-performance computing service, which is funded by the Office of Science and Technology through EPSRC's High End Computing Programme (Grant no. EP/L000202). We also acknowledge use of Hartree Centre resources in this work through the Energy Materials: Computational Solutions EPSRC project (EP/ K016288/1). In particular the author's would like to acknowledge the computational support of Alin Marin Elena. We thank Jarvist M. Frost and Keith T. Butler for fruitful discussions, and Mark Weller, Oliver Weber and Chris Bowen for support and discussions during early stages of the project.

\section{References}

1 N. M. Haegel, R. Margolis, T. Buonassisi, D. Feldman, A. Froitzheim, R. Garabedian, M. Green, S. Glunz, H.-M. Henning, B. Holder, I. Kaizuka, B. Kroposki, K. Matsubara, S. Niki, K. Sakurai, R. A. Schindler, W. Tumas, E. R. Weber, G. Wilson, M. Woodhouse and S. Kurtz, Science, 2017, 356, 141-143.

2 A. Polman, M. Knight, E. C. Garnett, B. Ehrler and W. C. Sinke, Science, 2016, 352, aad4424.

3 W. Shockley and H. J. Queisser, J. Appl. Phys., 1961, 32, 510. 4 L. Yu and A. Zunger, Phys. Rev. Lett., 2012, 108, 068701.

5 S. S. Shin, E. J. Yeom, W. S. Yang, S. Hur, M. G. Kim, J. Im, J. Seo, J. H. Noh and S. I. Seok, Science, 2017, 356, 167-171.

6 M. A. Green, A. Ho-Baillie and H. J. Snaith, Nat. Photonics, 2014, 8, 506-514.

7 S. K. Wallace, D. B. Mitzi and A. Walsh, ACS Energy Lett., 2017, 2, 776-779.

8 I. L. Repins, H. Moutinho, S. G. Choi, A. Kanevce, D. Kuciauskas, P. Dippo, C. L. Beall, J. Carapella, 
C. DeHart, B. Huang and S. H. Wei, J. Appl. Phys., 2013, 114, 084507.

9 N. M. Mangan, R. E. Brandt, V. Steinmann, R. Jaramillo, J. V. Li, J. R. Poindexter, K. Hartman, L. Sun, R. G. Gordon and T. Buonassisi, 2014 IEEE 40th Photovoltaic Specialist Conference (PVSC), 2014.

10 S. D. Stranks, G. E. Eperon, G. Grancini, C. Menelaou, M. J. P. Alcocer, T. Leijtens, L. M. Herz, A. Petrozza and H. J. Snaith, Science, 2013, 342, 341-344.

11 Q. Dong, Y. Fang, Y. Shao, P. Mulligan, J. Qiu, L. Cao and J. Huang, Science, 2015, 347, 967-970.

12 R. E. Brandt, V. Stevanović, D. S. Ginley and T. Buonassisi, MRS Commun., 2015, 5, 265-275.

13 J. M. Frost, K. T. Butler, F. Brivio, C. H. Hendon, M. van Schilfgaarde and A. Walsh, Nano Lett., 2014, 14, 2584-2590.

14 H. Guo, P. Liu, S. Zheng, S. Zeng, N. Liu and S. Hong, Curr. Appl. Phys., 2016, 16, 1603-1606.

15 P. Wang, J. Zhao, L. Wei, Q. Zhu, S. Xie, J. Liu, X. Meng and J. Li, Nanoscale, 2017, 9, 3806-3817.

16 Y. Rakita, O. Bar-Elli, E. Meirzadeh, H. Kaslasi, Y. Peleg, G. Hodes, I. Lubomirsky, D. Oron, D. Ehre and D. Cahen, Proc. Natl. Acad. Sci. U. S. A., 2017, 201702429.

17 E. I. Parkhomenko, Piezoelectric and Pyroelectric Effects in Minerals, Springer, US, 1971.

18 R. L. Bonewitz, Rocks and Minerals, Dorling Kindersley, Ltd, 2012.

19 V. M. Fridkin, Ferroelectric Semiconductors, Consultants Bureau, 1980.

20 S. Adachi, Earth-Abundant Materials for Solar Cells: Cu2-II-IVVI4 Semiconductors, Wiley, 2015.

21 A. M. Ganose, C. N. Savory and D. O. Scanlon, Chem. Commun., 2017, 53, 20-44.

22 R. E. Newnham, Properties of Materials, Oxford University Press, 2005.

23 T. L. Bahers, M. Rérat and P. Sautet, J. Phys. Chem. C, 2014, 118, 5997-6008.

24 K. T. Butler, J. M. Frost and A. Walsh, Energy Environ. Sci., 2015, 8, 838-848.

25 V. M. Fridkin, Photoferroelectrics, Springer-Verlag, Berlin, Heidelberg, 1979.

26 B. I. Sturman and V. M. Fridkin, Photovoltaic and Photorefractive Effects in Noncentrosymmetric Materials, Gordon and Breach Science Publishers, 1992.

27 A. G. Chynoweth, Phys. Rev., 1956, 102, 705-714.

28 M. R. Morris, S. R. Pendlebury, J. Hong, S. Dunn and J. R. Durrant, Adv. Mater., 2016, 28, 7123-7128.

29 J. Starkiewicz, L. Sosnowski and O. Simpson, Nature, 1946, 158, 28.

30 H. R. Johnson, R. H. Williams and C. H. B. Mee, J. Phys. D: Appl. Phys., 1975, 8, 1530-1541.

31 B. Goldstein and L. Pensak, J. Appl. Phys., 1959, 30, 155-161.

32 M. D. Uspenskii, N. G. Ivanova and I. E. Malkis, Sov. Phys. Semicond., 1968, 1059.

33 Y. Yuan, Z. Xiao, B. Yang and J. Huang, J. Mater. Chem. A, 2014, 2, 6027-6041.
34 C. Paillard, X. Bai, I. C. Infante, M. Guennou, G. Geneste, M. Alexe, J. Kreisel and B. Dkhil, Adv. Mater., 2016, 28, 5153-5168.

35 W. S. Choi, M. F. Chisholm, D. J. Singh, T. Choi, G. E. Jellison and H. N. Lee, Nat. Commun., 2012, 3, 689.

36 K. T. Butler, S. McKechnie, P. Azarhoosh, M. van Schilfgaarde, D. O. Scanlon and A. Walsh, Appl. Phys. Lett., 2016, 108, 112103.

37 E. Fatuzzo, G. Harbeke, W. J. Merz, R. Nitsche, H. Roetschi and W. Ruppel, Phys. Rev., 1962, 127, 2036-2037.

38 M. A. García and J. Balenzategui, Renewable Energy, 2004, 29, 1997-2010.

39 H. Dittrich, A. Bieniok, U. Brendel, M. Grodzicki and D. Topa, Thin Solid Films, 2007, 515, 5745-5750.

40 B. Durant and B. A. Parkinson, 2016 IEEE 43rd Photovoltaic Specialists Conference (PVSC), 2016.

41 H. Dittrich, A. Stadler, D. Topa, H.-J. Schimper and A. Basch, Phys. Status Solidi A, 2009, 206, 1034-1041.

42 T. Pauporté and D. Lincot, Adv. Mater. Opt. Electron., 1995, 5, 289-298.

43 N. I. Butsko, I. D. Zhezhnich and M. M. Pidorya, Russ. Phys. J., 1973, 16, 223-224.

44 Y. Dong, A. R. Khabibullin, K. Wei, J. R. Salvador, G. S. Nolas and L. M. Woods, ChemPhysChem, 2015, 16, 3264-3270.

45 J. J. Scragg, J. T. Wätjen, M. Edoff, T. Ericson, T. Kubart and C. Platzer-Björkman, J. Am. Chem. Soc., 2012, 134, 1933019333.

46 V. Blum, R. Gehrke, F. Hanke, P. Havu, V. Havu, X. Ren, K. Reuter and M. Scheffler, Comput. Phys. Commun., 2009, 180, 2175-2196.

47 X. Ren, P. Rinke, V. Blum, J. Wieferink, A. Tkatchenko, A. Sanfilippo, K. Reuter and M. Scheffler, New J. Phys., 2012, 14, 053020.

48 V. Havu, V. Blum, P. Havu and M. Scheffler, J. Comput. Phys., 2009, 228, 8367-8379.

49 S. V. Levchenko, X. Ren, J. Wieferink, R. Johanni, P. Rinke, V. Blum and M. Scheffler, Comput. Phys. Commun., 2015, 192, 60-69.

50 A. C. Ihrig, J. Wieferink, I. Y. Zhang, M. Ropo, X. Ren, P. Rinke, M. Scheffler and V. Blum, New J. Phys., 2015, 17, 093020.

51 J. Heyd, G. E. Scuseria and M. Ernzerhof, J. Chem. Phys., 2003, 118, 8207-8215.

52 W. P. Huhn and V. Blum, arXiv preprint: 1705.01804, 2017.

53 E. N. Brothers, A. F. Izmaylov, J. O. Normand, V. Barone and G. E. Scuseria, J. Chem. Phys., 2008, 129, 011102.

54 A. J. Garza and G. E. Scuseria, J. Phys. Chem. Lett., 2016, 7, 4165-4170.

55 G. Bergerhoff and I. Brown, Crystallographic Databases, 1987.

56 K. Momma and F. Izumi, J. Appl. Crystallogr., 2011, 44, 12721276.

57 C. Ambrosch-Draxl and J. O. Sofo, Comput. Phys. Commun., 2006, 175, 1-14.

58 N. A. Spaldin, J. Solid State Chem., 2012, 195, 2-10.

59 K. L. Svane and A. Walsh, J. Phys. Chem. C, 2016, 121, 421429. 
60 G. Kresse and J. Furthmüller, Comput. Mater. Sci., 1996, 6, 15-50.

61 G. Kresse and J. Furthmüller, Phys. Rev. B: Condens. Matter Mater. Phys., 1996, 54, 11169-11186.

62 P. E. Blöchl, Phys. Rev. B: Condens. Matter Mater. Phys., 1994, 50, 17953-17979.

63 R. Shuey, Semiconducting Ore Minerals, Elsevier, 2012.

64 L. L. Baranowski, P. Zawadzki, S. Lany, E. S. Toberer and A. Zakutayev, Semicond. Sci. Technol., 2016, 31, 123004.

65 F. J. Espinosa-Faller, D. R. Conradson, S. C. Riha, M. B. Martucci, S. J. Fredrick, S. Vogel, A. L. Prieto and S. D. Conradson, J. Phys. Chem. C, 2014, 118, 26292-26303.

66 S. Schorr, H.-J. Hoebler and M. Tovar, Eur. J. Mineral., 2007, 19, 65-73.

67 J. J. S. Scragg, L. Choubrac, A. Lafond, T. Ericson and C. Platzer-Björkman, Appl. Phys. Lett., 2014, 104, 041911.

68 D. Shin, B. Saparov, T. Zhu, W. P. Huhn, V. Blum and D. B. Mitzi, Chem. Mater., 2016, 28, 4771-4780.

69 Z. Xiao, W. Meng, J. V. Li and Y. Yan, ACS Energy Lett., 2017, 2, 29-35.

70 T. Gershon, K. Sardashti, O. Gunawan, R. Mankad, S. Singh, Y. S. Lee, J. A. Ott, A. Kummel and R. Haight, Adv. Energy Mater., 2016, 6, 1601182.

71 D. Shin, B. Saparov and D. B. Mitzi, Adv. Energy Mater., 2017, 1602366.

72 P. Velásquez, D. Leinen, J. Pascual, J. Ramos-Barrado, R. Cordova, H. Gómez and R. Schrebler, J. Electroanal. Chem., 2000, 494, 87-95.

73 L. Yu, R. S. Kokenyesi, D. A. Keszler and A. Zunger, Adv. Energy Mater., 2013, 3, 43-48.

74 S. Curtarolo, W. Setyawan, G. L. Hart, M. Jahnatek, R. V. Chepulskii, R. H. Taylor, S. Wang, J. Xue, K. Yang, O. Levy, M. J. Mehl, H. T. Stokes, D. O. Demchenko and D. Morgan, Comput. Mater. Sci., 2012, 58, 218-226.

75 B. Silvi and A. Savin, Nature, 1994, 371, 683-686.

76 A. Walsh, A. A. Sokol, J. Buckeridge, D. O. Scanlon and C. R. A. Catlow, J. Phys. Chem. Lett., 2017, 8, 2074-2075.
77 A. Zakutayev, C. M. Caskey, A. N. Fioretti, D. S. Ginley, J. Vidal, V. Stevanovic, E. Tea and S. Lany, J. Phys. Chem. Lett., 2014, 5, 1117-1125.

78 S. B. Zhang, S.-H. Wei, A. Zunger and H. Katayama-Yoshida, Phys. Rev. B: Condens. Matter Mater. Phys., 1998, 57, 96429656.

79 C. Persson and A. Zunger, Phys. Rev. Lett., 2003, 91, 266401.

80 C. Persson and A. Zunger, Appl. Phys. Lett., 2005, 87, 211904.

81 R. B. Balow, C. K. Miskin, M. M. Abu-Omar and R. Agrawal, Chem. Mater., 2017, 29, 573-578.

82 S. D. Wolf, J. Holovsky, S.-J. Moon, P. Löper, B. Niesen, M. Ledinsky, F.-J. Haug, J.-H. Yum and C. Ballif, J. Phys. Chem. Lett., 2014, 5, 1035-1039.

83 F. Brivio, A. B. Walker and A. Walsh, APL Mater., 2013, 1, 042111.

84 C. Eames, J. M. Frost, P. R. F. Barnes, B. C. O'Regan, A. Walsh and M. S. Islam, Nat. Commun., 2015, 6, 7497.

85 A. Y. Orlova, R. R. Gainov, A. V. Dooglav, I. N. Pen'kov and E. A. Korolev, JETP Lett., 2012, 96, 370-374.

86 K. Wei, J. Martin, J. R. Salvador and G. S. Nolas, Cryst. Growth Des., 2015, 15, 3762-3766.

87 R. Pandeya, G. Vatsc, J. Yund, C. R. Bowen, A. W. Y. HoBaillied and J. Seidel, arXiv preprint: 1705.05529, 2017.

88 P. S. Brody, Appl. Phys. Lett., 1981, 38, 153-155.

89 H.-Y. Huang, M. Wu and L.-J. Qiao, Comput. Mater. Sci., 2014, 82, 1-4.

90 R. Wahl, D. Vogtenhuber and G. Kresse, Phys. Rev. B: Condens. Matter Mater. Phys., 2008, 78, 104116.

91 Y. Xu, Ferroelectric Materials and Their Applications, NorthHolland, 1991.

92 I. Grinberg and A. M. Rappe, Phys. Rev. B: Condens. Matter Mater. Phys., 2004, 70, 220101.

93 P. Azarhoosh, S. McKechnie, J. M. Frost, A. Walsh and M. van Schilfgaarde, APL Mater., 2016, 4, 091501.

94 F. Zheng, L. Z. Tan, S. Liu and A. M. Rappe, Nano Lett., 2015, 15, 7794-7800.

95 L. D. Whalley, J. M. Frost, Y.-K. Jung and A. Walsh, J. Chem. Phys., 2017, 146, 220901. 